\title{
Effectiveness of physiotherapy and minimal invasive technics on functional status and quality of life in geriatric patients with low back pain
}

\author{
Özlem Ülger ${ }^{1, *}$, Aynur Demirel', Müzeyyen Oz' , Altan Şahin² \\ 'Department of Physiotherapy and Rehabilitation, Faculty of Health Sciences, Hacettepe University, Ankara, Turkey \\ ${ }^{2}$ Department of Anesthesiology, Faculty of Medicine, Hacettepe University, Ankara, Turkey
}

The aim of the study was to determine the effect of physiotherapy and minimal invasive technics (MIT) on pain, quality of life and functional disability in geriatric patients with chronic low back pain. According to previous files, 61 geriatric patients who received MIT and physiotherapy allocated to group 1, the patient who received physiotherapy alone allocated to group 2. All patients received soft tissue mobilizations, muscle-energy technics and spinal stabilization exercises. Pain severity, functional disability, life quality, and fear avoidance were assessed with visual analogue scale, Oswestry Disability Index (ODI), Nottingham
Health Profile (NHP) and Fear Avoidance Beliefs Questionnaire, respectively. Improvements in ODI and NHP were seen in favor of group 2 after treatment as to baseline $(P<0.05)$. Although both treatments showed pain relief, functional restoration, and improvement in quality of life; there was no additional improvement in patients received MIT different from the patients received physiotherapy alone.

Keywords: Physiotherapy, Exercise, Minimal invasive technics, Pain, Quality of life, Functional disability

\section{INTRODUCTION}

Low back pain (LBP) is a common disorder, which causes disability and widespread pain in elderly population (Bressler et al., 1999; Leveille et al., 1999; Prince et al., 2015; Reid et al., 2005). It is the common secondary cause of seeing a doctor among patients who are at the age of 65 and older (Cypress, 1983). The prevalence of LBP has increased to the age of 60 due to occupational exposure (Balagué and Pellisé, 2016) and decreased to the age of 60 and over in terms of changing perceived pain and apathy (Bernabei et al., 1998; Björck-van Dijken et al., 2008; Docking et al., 2011; Gibson and Helme, 2001; Papageorgiou et al., 1995; Thomas et al., 2004; Walsh et al., 1992). Eighty percent of older population has suffered form severe LBP and required long-term maintenance due to musculoskeletal system disorders. One third of this ratio constitutes from LBP and there is no adequate treatment, which is described for resolving pain in the elderly population.

${ }^{\star}$ Corresponding author: Özlem Ülger (D https://orcid.org/0000-0002-3908-223X Department of Physiotherapy and Rehabilitation, Faculty of Health Sciences, Hacettepe University, Ankara 06100, Turkey

Tel: +90-532-4027876, Fax: +90-312-3052012, E-mail: ozlemulger@yhaoo.com Received: July 27, 2018 / Accepted: August 29, 2018
Physical, psychological, and functional disorders accompanied with LBP and aging are increased impact of these problems. Unresolved LBP due to inadequate treatments and changes in perception increase the dependency on house and causes social isolation by leading emotional problems such as depression and anxiety.

In addition to medical, surgical and physiotherapy application, minimal invasive technics (MIT) have been used in management of LBP. Recently, we have observed that clinically geriatric population and their caregivers prefer MIT rather than surgery. Although, there have been studies related to MIT in geriatric patients, there is no an evidence based study related to physiotherapy added MIT in this population. So the aim of this study is to determine the effectiveness of physiotherapy application to geriatric patient with LBP who has received MIT on pain severity, functional disability and life quality. 


\section{MATERIALS AND METHODS}

This retrospective study was performed with the patients' records from September 2015 to January 2017 after the approval of Institutional Review Board of the University of Hacettepe (approval number: GO 17/09-22). A total of 61 patients at the age of 60 and over were participated in the study. The inclusion criteria were to have pain for at least 3 months and undergone physiotherapy and rehabilitation. The exclusion criteria was to have neurologic disease additional to LBP, malignity, diabetes mellitus, dementia, organic cerebral dysfunction, and mental or cognitive impairments. According to patients' records and eligibility criteria, patients who received MIT and physiotherapy were labelled as group 1 and patients who received physiotherapy alone were labelled as group 2 .

The routinely physiotherapy application for every patient was consisted of 20 min of hot-pack, myofascial stretching, muscle energy technics, and spinal stabilization exercises. Postisometric relaxations for Musculus Quadratus Lumborum, piriformis muscles were used as the muscle energy technics. Target muscle was located in the stretching position and the patients were asked to contract the muscle almost $8 \mathrm{sec}$ up to submaximal. The spinal stabilization exercises started with diaphragm respiration and the cocontraction of transversus abdominus (TA) and core muscles, and moved on to intermediate and advanced level with the contraction of TA and Multifidus muscles, maintaining the contraction with different positions. Advancing in spinal stabilization exercise depends on the patient's capability of maintaining the positions. The patients had 12 sessions of physiotherapy twice a week during a 6-week period. One therapy session lasted almost $60 \mathrm{~min}$.

\section{Pain severity}

The pain severity was rated by patients before the first and the last session of the physiotherapy with Visual Analog Scale. The distance between marked point and the origin is recorded as pain severity perceived by patient (Price et al., 1983). The pain severity during activity and night was recorded from the files.

Table 1. Demographic data of subjects

\begin{tabular}{lccc}
\hline Variable & Group 1 & Group 2 & $P$-value \\
\hline Age $(\mathrm{yr})$ & $71.8 \pm 4.8$ & $70 \pm 5$ & 0.710 \\
Body mass index $\left(\mathrm{kg} / \mathrm{m}^{2}\right)$ & $23.7 \pm 11.3$ & $24.5 \pm 12$ & 0.903 \\
\hline
\end{tabular}

Values are presented as mean \pm standard deviation.

Group 1, patients who received minimal invasive technics and physiotherapy; group 2, patients who received physiotherapy alone.

\section{Functional disability}

Oswestry Disability Index (ODI) was used to measure functional disability levels This self-administered questionnaire consists of 10 items, each having a score of 0 to 5. ODI total scores ranges from 0 (no disability) to 50 (severe disability) (Yakut et al., 2004).

\section{Life quality}

Turkish version of Nottingham Health Profile (NHP) was used to measure the changes in perceived health status. It has six subgroups consisted of pain, physical activity, energy, sleep, social isolation, and emotional reactions which scored between 0 to 100 points. A high score in NHP indicates high level of impairment in health status (Kücükdeveci et al., 2000).

\section{Kinesiophobia}

Turkish version of Fear Avoidance and Belief Questionnaire (FABQ) was used to measure the changes in fear avoidance behavior in patients with chronic LBP (CLBP). FABQ has 16-item scale, while first part is concerned to physical activity related fear avoidance, second part is demonstrated work related to fear avoidance beliefs. Each item replied by patient is a 7-point likert type scale which indicates completely disagree to completely agree (Korkmaz et al., 2009).

\section{RESULTS}

Patients' age and body mass index (BMI) were given in Table 1 according to groups. There was no statistically difference between groups in terms of mean age and BMI $(P<0.05)$.

Clinical features of group 1 received MIT were shown in Table 2. According to Table 2, facet denervation was the most prevalent in MITs and radiofrequency ablation (RFA) was the common ap-

Table 2. Clinical features of group 1

\begin{tabular}{lccc}
\hline Type & $\begin{array}{c}\text { One minimal } \\
\text { invasive surgery }\end{array}$ & $\begin{array}{c}\text { Two minimal } \\
\text { invasive surgery }\end{array}$ & $\begin{array}{c}\text { More than } \\
\text { two minimal } \\
\text { invasive surgery }\end{array}$ \\
\hline Facet denervation & $18(50)$ & $2(5.6)$ & $1(2.8)$ \\
Radiofrequency ablasion & $3(8.3)$ & $10(27.8)$ & $7(19.6)$ \\
SELD & $9(25)$ & $1(2.8)$ & $2(5.6)$ \\
Epidural steroid enjection & $3(8.3)$ & $5(13.9)$ & $6(16.8)$ \\
Epiduroscopy & $1(2.8)$ & $2(5.6)$ & $3(8.4)$ \\
SIJ enjection & $1(2.8)$ & $2(5.6)$ & $0(0)$ \\
Discogel & $0(0)$ & $1(2.8)$ & $0(0)$ \\
\hline
\end{tabular}

Values are presented as number (\%).

Group 1, patients who received minimal invasive technics and physiotherapy; SELD, sacral epiduroscopic laser decompression; SIJ, sacroiliac joint. 
Table 3. Descriptive statistics and intragroup analyses

\begin{tabular}{|c|c|c|c|c|c|c|c|c|c|c|}
\hline \multirow{2}{*}{ Variable } & \multicolumn{4}{|c|}{ Group 1} & \multicolumn{4}{|c|}{ Group 2} & \multirow{2}{*}{$P$-value ${ }^{a)}$} & \multirow{2}{*}{$P$-value ${ }^{b}$} \\
\hline & Before Treatment & After Treatment & $z$ & $P$-value & Before Treatment & After Treatment & z & $P$-value & & \\
\hline VAS activity & $6.8 \pm 2.4$ & $4.5 \pm 3.1$ & -2.38 & $0.017^{*}$ & $6.3 \pm 2.8$ & $2.5 \pm 3$ & -2.04 & $0.041^{*}$ & 0.645 & 0.448 \\
\hline VAS night & $3.06 \pm 3.1$ & $1.4 \pm 2.9$ & -1.61 & 0.107 & $2.7 \pm 3.2$ & $3.3 \pm 2.7$ & -1.60 & 0.109 & 0.571 & 0.710 \\
\hline ODI & $50 \pm 18.3$ & $35.3 \pm 14.9$ & -3.41 & $0.001^{*}$ & $39.1 \pm 14.5$ & $30.2 \pm 13$ & -1.36 & 0.172 & $0.023^{*}$ & 0.531 \\
\hline \multicolumn{11}{|l|}{ Nottingham } \\
\hline Energy & $71.8 \pm 33.1$ & $55.8 \pm 36.6$ & -2.69 & $0.007^{*}$ & $45.2 \pm 37.8$ & $43.0 \pm 36.0$ & -1.41 & 0.157 & $0.014^{*}$ & 0.372 \\
\hline Pain & $56.8 \pm 30.8$ & $38.3 \pm 21.7$ & -2.20 & $0.028^{*}$ & $50.1 \pm 28.3$ & $40.1 \pm 22.9$ & -1.75 & 0.080 & 0.654 & 0.561 \\
\hline Emotional & $39.8 \pm 32.0$ & $23.6 \pm 29.9$ & -1.85 & 0.063 & $25.8 \pm 30.9$ & $16.0 \pm 18.0$ & -0.31 & 0.753 & 0.120 & 0.766 \\
\hline Sleep & $39.5 \pm 34.6$ & $30.0 \pm 33.1$ & -1.22 & 0.221 & $26.0 \pm 28.6$ & $13.1 \pm 14.1$ & -0.73 & 0.461 & 0.192 & 0.193 \\
\hline Social & $29.4 \pm 30.4$ & $19.3 \pm 25.9$ & -0.762 & 0.446 & $10.8 \pm 22.1$ & $5.5 \pm 10.1$ & -0.57 & 0.564 & $0.006^{*}$ & 0.148 \\
\hline Physical & $48.4 \pm 17.7$ & $44.3 \pm 14.1$ & -1.47 & 0.141 & $38.8 \pm 21.1$ & $29.3 \pm 17.7$ & -1.29 & 0.196 & 0.080 & $0.037^{*}$ \\
\hline Total & $275.5 \pm 141.2$ & $233.3 \pm 134.0$ & -1.33 & $0.04^{*}$ & $190.7 \pm 143.4$ & $152.4 \pm 91.9$ & -0.16 & 0.866 & 0.033 & 0.247 \\
\hline FABO & $23.2 \pm 23.3$ & $20.4 \pm 5.3$ & -0.339 & -0.73 & $15.2 \pm 7.1$ & $12.4 \pm 8.1$ & 0.96 & 0.334 & -0.73 & 0.059 \\
\hline
\end{tabular}

Group 1, patients who received minimal invasive technics and physiotherapy; group 2, patients who received physiotherapy alone; VAS, visual analogue scale; ODI, Oswestry Disability Index; FABQ, Fear Avoidance Beliefs Questionnaire; BPS, Back Performance Scale.

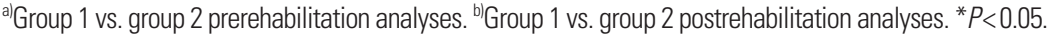

Table 4. Treatment (physiotherapy) and group effect

\begin{tabular}{lccccc}
\hline \multirow{2}{*}{ Variable } & \multicolumn{2}{c}{ Outcome change-treatment effect } & & \multicolumn{2}{c}{ Outcome change-group effect } \\
\cline { 2 - 3 } \cline { 5 - 6 } & $F$ & $P$-value & & $F$ & $P$-value \\
\cline { 5 - 6 } VAS activity & 12.11 & $0.002^{*}$ & & 0.17 & 0.679 \\
VAS night & 4.19 & 0.054 & & 0.33 & 0.570 \\
ODI & 17.32 & $<0.0001^{*}$ & & 3.32 & 0.082 \\
Nottingham & & & & \\
Energy & 4.34 & $0.050^{*}$ & & 11.64 & $0.003^{*}$ \\
Pain & 7.10 & $0.016^{*}$ & & 1.56 & 0.227 \\
Emotional & 2.65 & 0.121 & & 2.74 & 0.115 \\
Sleep & 1.96 & 0.178 & & 0.42 & 0.671 \\
Social & 0.45 & 0.508 & & 1.09 & 0.310 \\
Physical & 3.41 & 0.081 & & 0.20 & 0.657 \\
Total & 0.73 & 0.403 & & 0.58 & 0.455 \\
FABO & 1.95 & 0.180 & 0.48 & 0.490
\end{tabular}

VAS, visual analogue scale; ODI, Oswestry Disability Index; FABO, Fear Avoidance Beliefs Questionnaire.

${ }^{*} P<0.05$.

plication when patients received more than two MITs.

Reduction of pain severity during activity, improvements in ODI, NHP, and BPS were recorded in terms of outcomes, which were applied before and after the treatment. There was no significant difference in measured outcomes except ODI and NHP $(P>$ $0.05)$. Before treatment, improvements in ODI and NHP were seen in favor of group $2(P<0.05)$. No significant differences were seen except NHP-physical sub parameter (Table 3).

Treatment (physiotherapy) effect of measured outcomes and ad- ditional group (MIT) effect on treatments were shown in Table 4. The only significant difference was in VAS activity, ODI and NHP energy and pain subparameter $(P<0.05)$. The only difference was recorded in NHP health sub parameter in favor of group 1 , which is shown in right column of Table $4(P<0.05)$.

\section{DISCUSSION}

Current study was conducted to determine whether physiotherapy was effective in pain, functional status and quality of life in geriatric patients with CLBP who received MIT. It showed that both treatments had effective on the reduction in pain, functional restoration and quality of life. The results of the current study was similar with the literature in terms of the most common approaches were facet denervation and RFA.

According to the study, reductions in pain severity, disability, and costs associated with pain and opioid usage and increment in patient satisfaction after RFA are seen. Although positive improvements last for 6 months, they quietly decrease after 6 months (Burnham et al., 2009). The repetitive radiofrequency applications - twice or even three times in 6 months - showed that it has short-term benefits. This result showed the necessity of treatments that should be supported by the physiotherapy applications.

There was no consensus related to the effectiveness of physiotherapy after MIT when it was applied. According to algologist suggestions, if no complication develops, physiotherapy can be applied after 3 days for epidural steroid injection, after 1 week for 
RFA and after 2 weeks for SELD. Based on our experience, we executed these periods for geriatric population. Muscle spasm can be seen after MIT especially in acute period and it causes LBP (Koldaş Doğan et al., 2008).

Although, pain severity is lesser in young adults compared to geriatric population due to apathy, muscle spasm after MIT is felt intensively in geriatric population. In acute stages of MIT, soft tissue technics are highly preferred by physiotherapists. In the current study, manual therapy included superficial heat agents, muscle relaxing and muscle-energy technics were applied and it helped increasing blood flow through muscles, resolving muscle spasm and breaks the pain-spasm-pain circle (Koldaş Doğan et al., 2008). It is also recommended that physiotherapy methods are effective in painful stages for resolving muscle spasm, decreasing pain severity and preparing patients for exercise therapy in geriatric patients with CLBP (Wong et al., 2017). The reduction of pain severity in current study can be interpreted thanks to the physiotherapy applications in both groups.

It was known that fear avoidance reactions and functional loss were developed associated with pain in geriatric patients with CLBP (Wong et al., 2017). Especially, fear of falling is highly correlated with older age (Scheffer et al., 2008). In all patients with CLBP who applied to Back and Neck Health Unit had functional disability at different stages, which caused performance loss and reduction in the quality of life. Literature has also supported the fact that geriatric patients who have back and neck disorders encountered problems with social role that causes social isolation (Jordan et al., 2008; Matthews et al., 2005).

The present study and literature also confirmed that the patients in both groups gained relaxation in connective tissue and functional restoration related to pain relief at the end of the therapy. Besides physiotherapy applications, being able to move around more comfortably, staying away from home environment and transferring to the hospital with car or public transport had positive influence on pain relief and functional restoration. It is not surprising that social isolation could be developed in geriatric patients who could not receive any treatment at hospital or home care. It is important to participate to active treatment process to prevent social isolation. In the current study, physiotherapist guided exercise program and regular follow-up had positive impact on increment of the life quality. Group 2 was found to be more effective particularly in terms of subparameters of the life quality. These results caused the fact that the patients who received MIT emerged physical activity limitation prevent the harvest side of MIT.
Baseline outcomes of the patient received MIT were more effective than the outcomes of the other group. The possible causes of this may be late application to the hospital, applying hospital with unbearable pain or letting the receive intervention at the last stage. Other possible cause of this may be that ideal patient for MIT was the one that had neuropathic pain and frequently evoked pain by physical activity (Chou et al., 2018).

Although baseline measures were higher in group 1, after physiotherapy application improvements recorded and the difference between groups ended. According to these results, the principal factor to gain improvement was physiotherapy applications. In other words, there was no additional improvement between patients who received MIT and patients who received physiotherapy alone.

Some limitations were noted for this study. Due to the first application center is algology department and referral to physiotherapy after interventions, there was no assessed outcome before MIT. In our country, health insurance companies paid for MIT after all noninvasive treatments such as physiotherapy and conventional approaches is tried and failed. So the study is lacking informative data about the patients received what kind of therapies till they reached MIT.

It is obvious that the current study has an important role on chronic pain management setting in geriatric population in terms of determining the effectiveness of two different methods. Physiotherapy applications were safe and feasible after MIT in geriatric patients with CLBP in terms of functional restoration, development of life quality and regaining older as a social individual. For further studies on the long-term pain relief, maintaining functional restoration and cost effectiveness calculation are needed to make precise comments.

\section{CONFLICT OF INTEREST}

No potential conflict of interest relevant to this article was reported.

\section{REFERENCES}

Balagué F, Pellisé F. Adolescent idiopathic scoliosis and back pain. Scoliosis Spinal Disord 2016;9;11:27.

Bernabei R, Gambassi G, Lapane K, Landi F, Gatsonis C, Dunlop R, Lipsitz L, Steel K, Mor V. Management of pain in elderly patients with cancer. SAGE Study Group. Systematic assessment of geriatric drug use via epidemiology. JAMA 1998;279:1877-1882. 
Björck-van Dijken C, Fjellman-Wiklund A, Hildingsson C. Low back pain, lifestyle factors and physical activity: a population based-study. J Rehabil Med 2008;40:864-869.

Bressler HB, Keyes WJ, Rochon PA, Badley E. The prevalence of low back pain in the elderly. A systematic review of the literature. Spine (Phila Pa 1976) 1999;24:1813-1819.

Burnham RS, Holitski S, Dinu I. A prospective outcome study on the effects of facet joint radiofrequency denervation on pain, analgesic intake, disability, satisfaction, cost, and employment. Arch Phys Med Rehabil 2009;90:201-205.

Chou R, Côté P, Randhawa K, Torres P, Yu H, Nordin M, Hurwitz EL, Haldeman S, Cedraschi C. The Global Spine Care Initiative: applying evidence-based guidelines on the non-invasive management of back and neck pain to low- and middle-income communities. Eur Spine J 2018;27(Suppl 6):851-860.

Cypress BK. Characteristics of physician visits for back symptoms: a national perspective. Am J Public Health 1983;73:389-395.

Docking RE, Fleming J, Brayne C, Zhao J, Macfarlane GJ, Jones GT; Cambridge City over-75s Cohort Study collaboration. Epidemiology of back pain in older adults: prevalence and risk factors for back pain onset. Rheumatology (Oxford) 2011;50:1645-1653.

Gibson SJ, Helme RD. Age-related differences in pain perception and report. Clin Geriatr Med 2001;17:433-456, v-vi.

Jordan KP, Thomas E, Peat G, Wilkie R, Croft P. Social risks for disabling pain in older people: a prospective study of individual and area characteristics. Pain 2008;137:652-661.

Koldaş Doğan S, Sonel Tur B, Kurtaiş Y, Atay MB. Comparison of three different approaches in the treatment of chronic low back pain. Clin Rheumatol 2008;27:873-881.

Korkmaz N, Akinci A, Yörükan S, Sürücü HS, Saraçbaşi O, Ozçakar L. Validation and reliability of the Turkish version of the fear avoidance beliefs questionnaire in patients with low back pain. Eur J Phys Rehabil Med 2009;45:527-535.

Kücükdeveci AA, McKenna SP, Kutlay S, Gürsel Y, Whalley D, Arasil T. The development and psychometric assessment of the Turkish version of the Nottingham Health Profile. Int J Rehabil Res 2000;23:31-38.

Leveille SG, Guralnik JM, Hochberg M, Hirsch R, Ferrucci L, Langlois J,
Rantanen T, Ling S. Low back pain and disability in older women: independent association with difficulty but not inability to perform daily activities. J Gerontol A Biol Sci Med Sci 1999;54:M487-493.

Matthews RJ, Smith LK, Hancock RM, Jagger C, Spiers NA. Socioeconomic factors associated with the onset of disability in older age: a longitudinal study of people aged 75 years and over. Soc Sci Med 2005;61:1567-1575.

Papageorgiou AC, Croft PR, Ferry S, Jayson MI, Silman AJ. Estimating the prevalence of low back pain in the general population. Evidence from the South Manchester Back Pain Survey. Spine (Phila Pa 1976) 1995;20:1889-1894.

Price DD, McGrath PA, Rafii A, Buckingham B. The validation of visual analogue scales as ratio scale measures for chronic and experimental pain. Pain 1983;17:45-56.

Prince MJ, Wu F, Guo Y, Gutierrez Robledo LM, O'Donnell M, Sullivan R, Yusuf S. The burden of disease in older people and implications for health policy and practice. Lancet 2015;385:549-562.

Reid MC, Williams CS, Gill TM. Back pain and decline in lower extremity physical function among community-dwelling older persons. J Gerontol A Biol Sci Med Sci 2005;60:793-797.

Scheffer AC, Schuurmans MJ, van Dijk N, van der Hooft T, de Rooij SE. Fear of falling: measurement strategy, prevalence, risk factors and consequences among older persons. Age Ageing 2008;37:19-24.

Thomas E, Peat G, Harris L, Wilkie R, Croft PR. The prevalence of pain and pain interference in a general population of older adults: crosssectional findings from the North Staffordshire Osteoarthritis Project (NorStOP). Pain 2004;110:361-368.

Yakut E, Düger T, Oksüz C, Yörükan S, Ureten K, Turan D, Frat T, Kiraz S, Krd N, Kayhan H, Yakut Y, Güler C. Validation of the Turkish version of the Oswestry Disability Index for patients with low back pain. Spine (Phila Pa 1976) 2004;29:581-585.

Walsh K, Cruddas M, Coggon D. Low back pain in eight areas of Britain. J Epidemiol Community Health 1992;46:227-230.

Wong AY, Karppinen J, Samartzis D. Low back pain in older adults: risk factors, management options and future directions. Scoliosis Spinal Disord 2017;12:14. 